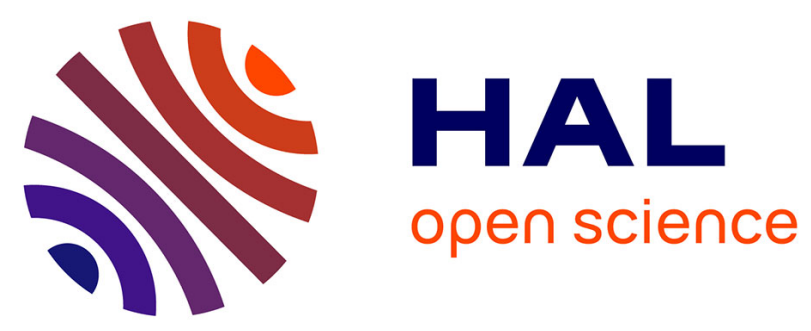

\title{
Evidence and quantitative evaluation of tensile maturation strain in flax phloem through longitudinal splitting
}

Tancrede Almeras, Anna Petrova, Liudmila Kozlova, Joseph Gril, Tatyana Gorshkova

\section{To cite this version:}

Tancrede Almeras, Anna Petrova, Liudmila Kozlova, Joseph Gril, Tatyana Gorshkova. Evidence and quantitative evaluation of tensile maturation strain in flax phloem through longitudinal splitting. Botany / Botanique, 2020, 98 (1), pp.9-19. 10.1139/cjb-2019-0021 . hal-02468523

\section{HAL Id: hal-02468523 \\ https://hal.science/hal-02468523}

Submitted on 5 Feb 2020

HAL is a multi-disciplinary open access archive for the deposit and dissemination of scientific research documents, whether they are published or not. The documents may come from teaching and research institutions in France or abroad, or from public or private research centers.
L'archive ouverte pluridisciplinaire HAL, est destinée au dépôt et à la diffusion de documents scientifiques de niveau recherche, publiés ou non, émanant des établissements d'enseignement et de recherche français ou étrangers, des laboratoires publics ou privés. 


\title{
Evidence and quantitative evaluation of tensile maturation strain in flax phloem through longitudinal splitting 1
}

\author{
Tancrède Alméras, Anna Petrova, Liudmila Kozlova, Joseph Gril, and Tatyana Gorshkova
}

\begin{abstract}
The stems of flax (Linum usitatissimum L. cv. 'Mogilevsky') contain many gelatinous fibers in their phloem. These fibers are important for the mechanical stability of the plant as well as for industrial applications. Gelatinous fibers are known to have a motor function in the xylem of trees and in many plant organs. This function arises from the so-called maturation strain, i.e., the tendency of the gelatinous layer to shrink during fiber maturation, resulting in a state of residual tensile stress. However, the occurrence of tensile maturation strain in flax phloem fibers remains to be demonstrated, and its magnitude has never been evaluated. Here we present a novel method to highlight and quantify this strain. The method consists in splitting a stem segment longitudinally, and measuring the curvature of the half segments through their opening distance. By using a mechanical model, the maturation strain can be calculated from the curvature, the dimensions of the component tissues, and their elastic properties. The model is validated by the agreement between model predictions and observations. The splitting experiment provides qualitative evidence that flax phloem develops tensile stress during maturation, just as xylem gelatinous fibers do. Calculations enable quantitative estimation of the maturation strain. The magnitude of this strain for the material studied is, on average, $-1.5 \%$.
\end{abstract}

Key words: flax, bast fibers, gelatinous fibers, tension, stem splitting, maturation strain.

Résumé : Les tiges du lin (Linum usitatissimum L. cv. 'Mogilevsky') contiennent plusieurs fibres gélatineuses dans leur phloème. Ces fibres sont importantes pour la stabilité mécanique de la plante de même que pour ses applications industrielles. Les fibres gélatineuses sont connues pour avoir une fonction motrice dans le xylème des arbres et dans plusieurs organes végétaux. Cette fonction provient de ce que l'on appelle une tension de maturation, c'est-à-dire la tendance de la couche gélatineuse à se contracter lors de la maturation des fibres, donnant lieu à un état de contrainte de traction résiduelle. Toutefois, l'existence d'une tension de maturation par traction dans les fibres du phloème du lin reste à démontrer, et son ampleur n'a jamais été évaluée. Les auteurs présentent ici une nouvelle méthode qui permet de mettre en évidence et de quantifier cette tension. La méthode consiste à scinder un segment de la tige de manière longitudinale et à mesurer la courbure des demi-segments par la distance de leur ouverture. En utilisant un modèle mécanique, la tension de maturation peut être calculée à partir de la courbure, des dimensions des tissus constituants et de leurs propriétés élastiques. Le modèle est validé par la concordance entre les prédictions du modèle et les observations. L'expérience de scission fournit une preuve qualitative que le phloème du lin développe une contrainte de traction lors de la maturation, tout comme le font les fibres gélatineuses du xylème. Les calculs rendent possible une estimation quantitative de la tension de maturation. L'ampleur de cette tension pour le matériel étudié est de -1,5\% en moyenne. [Traduit par la Rédaction]

Mots-clés : lin, fibre du liber, fibres gélatineuses, tension, division de la tige, tension de maturation.

\section{Introduction}

Flax plants, like other fiber crops, have straight standing stems with a high height to width ratio (Goudenhooft et al. 2019). The ability of such long but narrow stems to withstand both external mechanical loads, like that pro- vided by wind, and internal mechanical loads, like those originating from growth, is considered to be linked with the development of bast (phloem) fibers (Gorshkova et al. 2012). Unless the specific properties of such fibers are taken into account, stem slenderness in such plants is

Received 28 January 2019. Accepted 31 August 2019.

T. Alméras. LMGC, Université de Montpellier, CNRS - CC048, 163 rue Auguste Broussonnet, 34090 Montpellier, France.

A. Petrova, L. Kozlova, and T. Gorshkova. Kazan Institute of Biochemistry and Biophysics, FRC Kazan Scientific Center of RAS, 420111 Lobachevsky Str. 2/31, Kazan, Russia.

J. Gril. CNRS, Université Clermont Auvergne, Sigma Clermont, Institut Pascal, Campus des Cezeaux, 2 avenue Blaise Pascal, 63178 Aubière cedex, France; INRA, Université Clermont Auvergne, PIAF - Site de Crouël, 5 chemin de Beaulieu, 63000 Clermont-Ferrand, France.

Corresponding author: Tancrède Alméras (email: tancrede.almeras@umontpellier.fr).

${ }^{1}$ This Article is part of a Special issue from the 9th International Plant Biomechanics Conference (9-14 August 2018, McGill University). Copyright remains with the author(s) or their institution(s). Permission for reuse (free in most cases) can be obtained from RightsLink. 
higher than the predicted theoretical limit (Bourmaud et al. 2018).

Flax fibers belong to the so-called "gelatinous fibers" that are widespread in plants of many taxa, can be present in various plant parts, and are described as "plant muscles" (Gorshkova et al. 2018). They have special composition and architecture of the cell wall, which is named either the G-layer of secondary cell wall (Clair et al. 2019), or tertiary cell wall (Gorshkova et al. 2018). The effects provided by such fibers include visible organ contraction, as observed in roots and hypocotyls of geophytes (Fisher 2008; Schreiber et al. 2010), or in aerial roots (Fisher 1982; Abasolo et al. 2009), as well as the formation of stem curvature in the course of negative gravitropic reaction, like in tension wood of most angiosperm tree species (Dadswell and Wardrop 1955; Alméras et al. 2009). Most of these effects are caused by the gelatinous fibers developed in the xylem tissues of an organ. The mechanical stress needed to position plant parts is induced by cellulose microfibril tension that develops during the formation of the gelatinous fiber (Clair et al. 2011). The emerging tensile maturation stress is evidenced through the strains that occur when the stress is artificially released, sometimes called "released maturation strains". Maturation strains have been detected and quantified in tree stems using several approaches, including extensometers (Clair et al. 2006a; Jullien and Gril 2008), strain gauges (Yoshida and Okuyama 2002; Clair et al. 2013), X-ray diffraction (Clair et al. 2006b, 2011), and inverse methods based on measuring curvature (Alméras et al. 2009, 2018).

In many herbaceous species, for example in the majority of fiber crops, like flax, hemp and ramie, gelatinous fibers develop within the phloem (Gorshkova et al. 2012; Bourmaud et al. 2018). The impressive mechanical properties of phloem fibers are quite renowned (Bos et al. 2002; Aslan et al. 2011; Tanguy et al. 2016; Arnould et al. 2017; Ahmed and Ulven 2018); their importance for stem mechanical performance has been demonstrated in numerous studies (Goudenhooft et al. 2017, 2018, 2019; Baley et al. 2018; Réquilé et al. 2018). However, "muscle type" effects of phloem fibers, which are linked to the development of tension, are not as apparent as in the case of organ contraction or stem curvature provided by xylem fibers. Presence of tension in stems with phloemlocated gelatinous fibers can be assumed, because of similarities between the general composition and architecture of their cell walls and those of gelatinous fibers in wood (Mellerowicz and Gorshkova 2012; Gorshkova et al. 2012, 2015), but this state of tension has never been conclusively demonstrated, and its magnitude has never been evaluated.

At least two problems arise when trying to evaluate the maturation stress in the phloem of fiber crops. The first is how to measure residual strains on such small stems. Methods routinely used for tree stems cannot be used directly on small stems, because of the finite size of the sensors. The second problem concerns the relationship between released strain and maturation strain. When released strain is measured at the surface of tree xylem, it is assumed to be equal to maturation strain. This assumption is justified because developing xylem located just below the bark is prevented from straining during maturation by the stiff inner core of mature xylem (Archer 1986). Therefore, the mechanical state of the xylem located at the periphery of wood is equal to that set by maturation, and the released strain consequently equals the maturation strain. The case of fiber crops may be a bit different. Because developing phloem fibers represent a large proportion of stem stiffness compared to the stiffness of other component tissues (Goudenhooft et al. 2018), the fibers are not completely prevented from straining during their maturation. Part of the stress set during maturation is expressed in vivo, because nonnegligible contraction of the whole stem occurs in response to maturation stress. This contraction will set compressive stress in xylem and reduce the tension in phloem: only a fraction of the initial maturation stress in the phloem remains and potentially contributes to artificially released strains. Thus, even if the problem of measuring the residual strain on a small stem is overcome, the measurement will underestimate the native maturation strain.

Here we present an original method to overcome these problems. The basic principle consists in splitting the stem longitudinally in two halves. If the component tissues are differentially stressed, then the two halves will bend, and mechanical theories make it possible to link the curvature to the state of stress of the tissues. This is an easy way to get around the problem of measuring the strain by measuring the curvature instead. It also avoids the problem of in vivo expressed strains. Indeed, the in vivo expression of phloem tensile stress during plant maturation occurs through the contraction of the stem, thereby compressing the xylem. The level of compressive strain set in the xylem is a marker of the in vivo expressed strain. While the stem is being split, the compressive stress in the xylem will also help bend the two halves of the stem. By jointly modeling the problem of in vivo strain and the problem of stem splitting it becomes possible to evaluate the native maturation strain from a measurement of the curvature of a split stem.

We applied this method to stems of flax plants - one of the best examples of highly developed gelatinous fibers located in the stem phloem. The stages of flax fiber formation have already been well characterized (Gorshkova et al. 2003), enabling us to choose the appropriate portion of the stem for the analysis. Flax only has primary phloem fibers that originate from procambium close to the apical meristem (Esau 1943), so interpreting the measurement is not complicated by the development of secondary phloem fibers. 
Fig. 1. (A) Schematic representation of a flax cross-section comprising three concentric layers: pith, xylem, and phloem. The dashed line represents the cutting line for the splitting experiment, located at a distance $d$ from the center of the section. (B) Opening a stem segment after asymmetric splitting: $a$ is the opening distance at the end of the right half of the segment. [Colour online.]
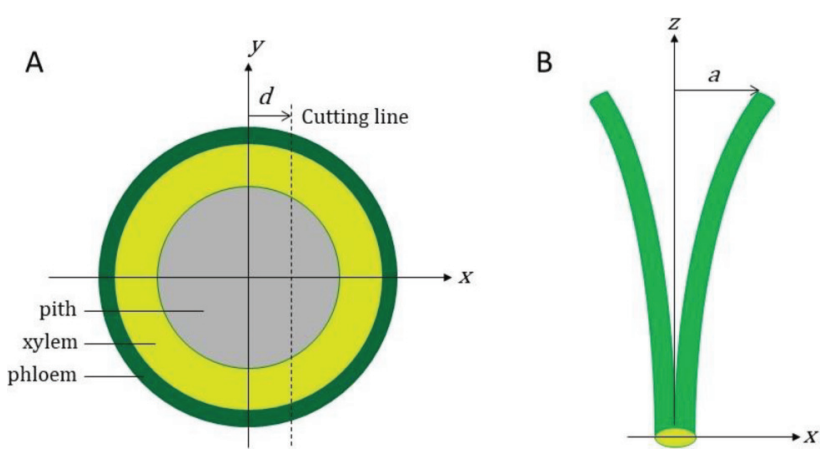

In this article, we use the splitting method to highlight and measure the maturation strain in phloem gelatinous fibers of flax stems. We describe the principles and theory behind the method, and demonstrate that flax phloem fibers develop strong tension during their maturation.

\section{Materials and methods}

Modeling phloem maturation and the splitting experiment

\section{General framework}

The stem is assumed to be made of two concentric layers (xylem and phloem) and a central part representing the pith (Fig. 1A). The mechanical contribution of the pith is neglected. As the stem (and the stem segment) is a slender structure, we set the problem in the framework of beam theory, neglecting end effects. We are only interested in the longitudinal component of stresses and strains. We model the longitudinal stresses and strains that appear in the tissues in response to two successive phenomena: the induction of maturation stress in phloem, and the longitudinal cutting of the stem segment. The maturation stress is modeled as an inelastic stress (analogous to a thermal stress) that appears in the phloem in response to physical and chemical changes occurring in the cell walls. Otherwise, the component materials are considered elastic, characterized by their moduli of elasticity $E_{\mathrm{xyl}}$ and $E_{\mathrm{phl}}$ for xylem and phloem, respectively. In the two problems (maturation stress induction and stem splitting), the system is not subject to external actions, and elastic strains appear in such a way that the field of stress becomes self-balanced.

\section{Modeling phloem maturation and in vivo strain}

We assume here that xylem is already mature during phloem maturation. Because phloem is much stiffer than xylem (Réquilé et al. 2018), we assume that any initial stress in xylem has much lower magnitude than the stress induced by phloem maturation, and can con- sequently be neglected. Let $\alpha_{\mathrm{phl}}^{\text {matur }}$ be the maturation strain of phloem, i.e., the virtual strain that would occur in phloem during maturation if it was not impeded by surrounding material. The reference state for definition of this strain is the stem just before phloem experiences maturation strain.

In response to this maturation strain, some elastic strains and stresses appear in the stem. Because the stem is modeled as a beam and the situation is axisymmetric, the field of strain will be uniform within the stem section. Let $\varepsilon_{\text {stem }}^{\text {in vivo }}$ be the strain of the stem that occurs in vivo in response to phloem maturation. Let $\sigma_{\text {xyl }}^{\text {in vivo }}$ and $\sigma_{\mathrm{phl}}^{\text {in vivo }}$ be respectively the in vivo state of stress of xylem and phloem. The elastic behavior of the tissues implies that the stress in xylem is proportional to stem strain:

$$
\sigma_{\mathrm{xyl}}^{\text {in vivo }}=E_{\mathrm{xyl}} \varepsilon_{\text {stem }}^{\text {in vivo }}
$$

The stress in phloem results from its elastic behavior with pre-strain:

$$
\sigma_{\mathrm{phl}}^{\text {in vivo }}=E_{\mathrm{phl}}\left(\varepsilon_{\mathrm{stem}}^{\text {in vivo }}-\alpha_{\mathrm{phl}}^{\text {matur }}\right)
$$

The condition for equilibrium is that the sum of all stresses on the section is null:

$$
\iint_{\text {xylem }+ \text { phloem }} \sigma^{\text {in vivo }} d A=0
$$

where $d A$ is an elementary surface area of the section. Injecting constitutive eqs. 1 and 2 into eq. 3 , and solving for $\varepsilon_{\text {stem }}^{\text {in vivo }}$ (see Appendix A for a detailed demonstration), we obtain:

$$
\varepsilon_{\text {stem }}^{\text {in vivo }}=\alpha_{\mathrm{phl}}^{\text {matur }} E_{\mathrm{phl}} A_{\mathrm{phl}} /\left(E_{\mathrm{xyl}} A_{\mathrm{xyl}}+E_{\mathrm{phl}} A_{\mathrm{phl}}\right)
$$

where $A_{\mathrm{yxl}}$ and $A_{\mathrm{phl}}$ are respectively the surface area of xylem and phloem. Let $c_{\mathrm{phl}}$ be the relative contribution of phloem to axial stiffness, defined as:

$$
c_{\mathrm{phl}}=E_{\mathrm{phl}} A_{\mathrm{phl}} /\left(E_{\mathrm{xyl}} A_{\mathrm{xyl}}+E_{\mathrm{phl}} A_{\mathrm{phl}}\right)
$$

The in vivo strain can be expressed as a function of the maturation strain and the relative contribution of phloem to stem axial stiffness by injecting eq. 5 into eq. 4:

$$
\varepsilon_{\text {stem }}^{\text {in vivo }}=c_{\mathrm{phl}} \alpha_{\mathrm{phl}}^{\text {matur }}
$$

Finally, the in vivo state of stress of the tissues at equilibrium is obtained by injecting eq. 6 into eq. 1 and eq. 2 :

$$
\begin{aligned}
& \sigma_{\mathrm{xyl}}^{\text {in vivo }}=c_{\mathrm{phl}} E_{\mathrm{xyl}} \alpha_{\mathrm{phl}}^{\text {matur }} \\
& \sigma_{\mathrm{phl}}^{\text {in vivo }}=\left(c_{\mathrm{phl}}-1\right) E_{\mathrm{phl}} \alpha_{\mathrm{phl}}^{\text {matur }}
\end{aligned}
$$


Modeling the splitting experiment

The splitting experiment consists of cutting a segment of a mature stem longitudinally. We assume that the cutting occurs in any line of the section (not necessarily through its diameter) located at a distance $d$ from the section center (Fig. 1A), then compute the curvature that appears in a given half segment (Fig. 1B). The curvature is the change in angle along the segment per unit length. When the cutting occurs, the axial symmetry of the problem is canceled so that the initial field of stress $\sigma^{\text {in vivo }}$ (resulting from tissue maturation and in vivo strain) is no longer at equilibrium. In response to this imbalance in stress, a field of strain $\varepsilon^{\text {split }}$ appears in the half segment. Because the problem is not axisymmetric, this field of strain is not uniform and depends on the position $(x, y)$ within the section (Fig. 1A). Let $\sigma^{\text {split }}$ be the field of stress at equilibrium. The elastic behavior of the tissues implies that:

$$
\begin{aligned}
& \sigma^{\text {split }}(x, y)-\sigma_{\text {xyl }}^{\text {in vivo }}=E_{\mathrm{xyl}} \varepsilon^{\text {split }}(x, y) \text { inside xylem } \\
& \sigma^{\text {split }}(x, y)-\sigma_{\mathrm{phl}}^{\text {in vivo }}=E_{\mathrm{phl}} \varepsilon^{\text {split }}(x, y) \quad \text { inside phloem }
\end{aligned}
$$

According to Bernoulli's hypothesis, the field of strain within a half-stem section is a plane (meaning that the magnitude of strain depends linearly on the coordinates). Because of the mirror symmetry with respect to the $X$-axis (Fig. 1), the curvature will only appear around the Y-axis, so that:

$$
\varepsilon^{\text {split }}(x, y)=\varepsilon_{\text {pith }}^{\text {split }}-x C
$$

where $\varepsilon_{\text {pith }}^{\text {split }}$ is the strain at a reference position taken at the center of the pith (or its virtual position if the pith is not contained in the half-section) and $C$ is the curvature that appears in the half segment after splitting.

The conditions for static equilibrium of the halfsegment are:

$$
\begin{aligned}
& \iint_{\text {half section }} \sigma^{\text {split }} d A=0 \\
& \iint_{\text {half section }} x \sigma^{\text {split }} d A=0
\end{aligned}
$$

By injecting eq. 8 and eq. 9 into eq. 10 (see Appendix A for a detailed demonstration), the conditions for equilibrium are reduced to the following system:

$$
\begin{array}{r}
\left(\begin{array}{rr}
E_{x y l} J_{x y l}^{0}+E_{p h l} J_{p h l}^{0} & -E_{\mathrm{xyl}} J_{\mathrm{xyl}}^{1}-E_{\mathrm{phl}} J_{\mathrm{phl}}^{1} \\
-E_{x y l} J_{x y l}^{1}-E_{p h l} J_{p h l}^{1} & E_{\mathrm{xyl}} J_{\mathrm{xyl}}^{2}+E_{\mathrm{phl}} J_{\mathrm{phl}}^{2}
\end{array}\right)\left(\begin{array}{c}
\varepsilon_{\mathrm{pith}}^{\text {split }} \\
C
\end{array}\right) \\
=-\sigma_{\mathrm{xyl}}^{\text {in vivo }}\left(\begin{array}{c}
J_{\mathrm{xyl}}^{0} \\
-J_{\mathrm{xyl}}^{1}
\end{array}\right)-\sigma_{\mathrm{phl}}^{\text {in vivo }}\left(\begin{array}{c}
J_{\mathrm{phl}}^{0} \\
-J_{\mathrm{phl}}^{1}
\end{array}\right)
\end{array}
$$

where $J_{\mathrm{xyl}}^{i}$ and $J_{\mathrm{phl}}^{i}$ are the moments of area of the tissues within the half section, defined as:

$$
\begin{aligned}
& J_{\mathrm{xyl}}^{i}=\iint_{\text {half xylem }} x^{i} d A \\
& J_{\mathrm{phl}}^{i}=\iint_{\text {half phloem }} x^{i} d A
\end{aligned}
$$

Injecting eqs. $7 a$ and $7 b$ into eq. 11 , we obtain:

$$
\begin{aligned}
& \left(\begin{array}{cc}
E_{\mathrm{xyl}} J_{\mathrm{xyl}}^{0}+E_{\mathrm{phl}} J_{\mathrm{phl}}^{0} & -E_{\mathrm{xyl}} J_{\mathrm{xyl}}^{1}-E_{\mathrm{phl}} J_{\mathrm{phl}}^{1} \\
-E_{\mathrm{xyl}} J_{\mathrm{xyl}}^{1}-E_{\mathrm{phl}} J_{\mathrm{phl}}^{1} & E_{\mathrm{xyl}} J_{\mathrm{xyl}}^{2}+E_{\mathrm{phl}} J_{\mathrm{phl}}^{2}
\end{array}\right)\left(\begin{array}{c}
\varepsilon_{\mathrm{pith}}^{\mathrm{split}} \\
C
\end{array}\right) \\
= & \alpha_{\mathrm{phl}}^{\operatorname{matur}}\left[-c_{\mathrm{phl}}\left(\begin{array}{c}
E_{\mathrm{xyl}} J_{\mathrm{xyl}}^{0} \\
-E_{\mathrm{xyl}} J_{\mathrm{xyl}}^{1}
\end{array}\right)+\left(1-c_{\mathrm{phl}}\right)\left(\begin{array}{c}
E_{\mathrm{phl}} J_{\mathrm{phl}}^{0} \\
-E_{\mathrm{phl}} J_{\mathrm{phl}}^{1}
\end{array}\right)\right]
\end{aligned}
$$

We denote $R$ as the inverse of the (symmetric) stiffness matrix, and $V$ as the right-hand vector. The strain at the pith and curvature can be expressed as a function of phloem maturation strain:

$$
\left(\begin{array}{c}
\varepsilon_{\text {pith }}^{\text {split }} \\
C
\end{array}\right)=\alpha_{\text {phl }}^{\text {matur }}\left(\begin{array}{ll}
R_{11} & R_{12} \\
R_{12} & R_{22}
\end{array}\right)\left(\begin{array}{c}
V_{1} \\
V_{2}
\end{array}\right)
$$

Finally, the maturation strain of phloem can be expressed as a function of the curvature of the half segment:

$$
\alpha_{\mathrm{phl}}^{\text {matur }}=C /\left(R_{12} V_{1}+R_{22} V_{2}\right)
$$

\section{Using the model to estimate phloem maturation strain}

Computation of maturation strain from eq. 15 requires three kinds of data: the moments of area of the phloem and xylem parts; the moduli of elasticity of the phloem and xylem tissues; and the curvature of the half segment. The moments of area of the cut rings can be computed from their inner and outer radii and the cutting distance, using formulae provided in Appendix A, and applying them successively to the xylem ring and the phloem ring.

From eq. 15, it can easily be shown that the maturation strain does not directly depend on the moduli of elasticity of phloem and xylem, but only on their ratio. Réquilé et al. (2018) measured the moduli of elasticity of phloem and xylem in flexural tests on flax stem segments and obtained a mean value of $55.8 \mathrm{GPa}$ for the phloem tissue. They obtained a mean value of $9.2 \mathrm{GPa}$ on xylem samples containing pith. This yields an estimated value of between 10 and 12 GPa for the xylem tissue once the contribution of the pith is removed. Although these values were obtained on dry stems, we assume that the ratio of the modulus of elasticity between phloem and xylem is the same as in the green state, taking a value of 0.2 for the $E_{\mathrm{xyl}}: E_{\mathrm{phl}}$ ratio. A sensitivity analysis on this parameter will be performed to evaluate the consequences of this approximation.

The curvature can be quantified from the opening distance of each half segment (Fig. 1). The half opening distance is obtained by double integration of the curvature, assumed to be constant along the split length: 
Fig. 2. Scheme of the experiment: (A) sample collection; (B) stem splitting; (C) cross-section analysis. [Colour online.]

A

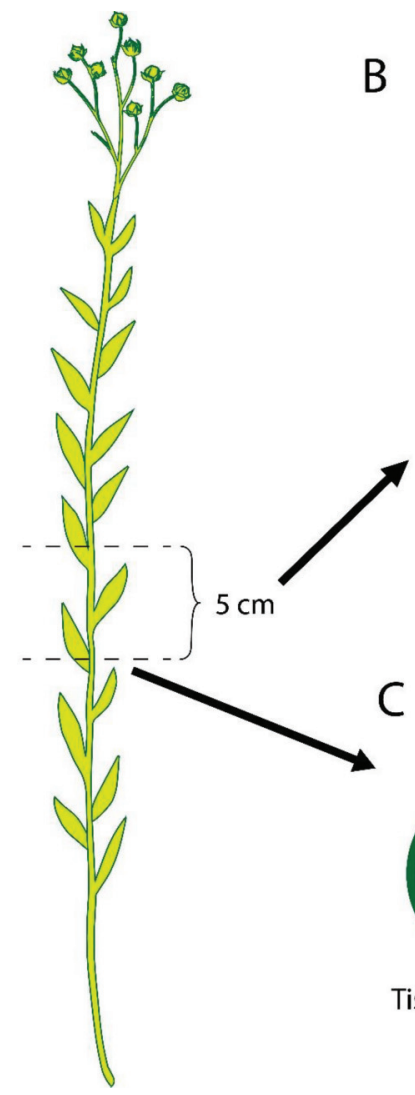

(16)

$$
a=\iint_{0}^{L} C(z) d z=\frac{1}{2} L^{2} C
$$

where $a$ is the half opening distance, $L$ is the split length, $C$ is the curvature, and $z$ is a position along the segment (counted from the base of the split portion). The curvature is therefore computed from measurements by inversion of this relation:

$$
C=\frac{2 a}{L^{2}}
$$

For a symmetric cut, $2 a$ represents the total opening distance.

\section{Experiments}

\section{Plant material}

Flax plants (Linum usitatissimum L. cv. 'Mogilevsky') from the collection belonging to the All-Russian Flax Research Institute (Torzhok, Russia) were grown in boxes, with a $50 \mathrm{~cm}$ layer of soil, in the open air, under natural light, and with daily watering. Plants $55-70 \mathrm{~cm}$ in height at yellow ripeness stage (100 days after sowing) were used for the experiments. At this stage of plant development, the elongation growth of all phloem fibers in a stem has ceased, and these cells thicken their cell wall (Gorshkova et al. 2003) (Fig. 2A). Fourteen segments of stem $5 \mathrm{~cm}$ in length were collected at a height of $20-30 \mathrm{~cm}$ above the ground for the stem splitting experiments.

\section{Stem splitting}

The top $4 \mathrm{~cm}$ of the $5-\mathrm{cm}$-long segments were cut longitudinally to split the segment into two longitudinal halves (leaving the basal one $\mathrm{cm}$ of the segment unsplit) (Fig. 2B). The cut was made through a diameter and was therefore symmetric. To measure the opening distances, each segment was placed on graph paper (for better scaling) and imaged using a digital camera within one minute of splitting to exclude the influence of drying.

Cross-sections were immediately cut above and below the studied 5-cm-long segments, and then imaged under a light microscope. The stem, cambium, and pith radii as well as opening distance were measured using ImageJ 1.52n software (Schneider et al. 2012). The sections were cut immediately above and below the studied segments to check whether the radii changed. Changes did not exceed $10 \%$, therefore average values of radii were used in further calculations for each segment.

\section{Results}

Parametric study of the model

The direct model (eq. 14) computes the curvature (and therefore, by combining it with eq. 16, the opening distance) of each of the two half segments from the maturation strain of phloem, the moduli of elasticity of the tissues and their moments of area (which depend on the radii of tissues $R_{\text {pith }}, R_{\text {cambium, }}$, and $R_{\text {stem }}$, and the cutting distance $d$, as detailed in Appendix A). From these equa- 
Table 1. Range of values used for the parametric study.

\begin{tabular}{lcl}
\hline & $\begin{array}{l}\text { Reference } \\
\text { value }\end{array}$ & Range \\
\hline$R_{\text {stem }}(\mathrm{mm})$ & 1.0 & $0.5-2.0$ \\
$R_{\text {cambium }}: R_{\text {stem }}$ & 0.9 & $0.6-1.0$ \\
$R_{\text {pith }}: R_{\text {stem }}$ & 0.6 & $0.0-0.9$ \\
$E_{\text {xyl }}: E_{\text {phl }}$ & 0.2 & $0.0-1.0$ \\
$d: R_{\text {stem }}$ & 0 & $0.0-1.0$ \\
$L(\mathrm{~mm})$ & 40 & - \\
$\alpha_{\text {mhl }}^{\text {matur }}$ & $-1 \%$ & - \\
\hline
\end{tabular}

Note: $R_{\text {stem }}$, radius of the stem; $R_{\text {cambium }}$, radius of the cambium (defining the thickness of phloem); $R_{\text {pith }}$, radius of the pith (defining the thickness of the xylem); $E_{x y l}$, modulus of elasticity of xylem; $E_{\mathrm{phl}}$, modulus of elasticity of phloem; $d$, distance from the cutting line to the center of the section; L, length of the longitudinal cut; $\alpha_{\mathrm{phl}}^{\text {matur }}$, maturation strain of phloem.

tions, it is apparent that the opening distance is proportional to the maturation strain. It can also be shown that the opening distance does not depend on the magnitude of the moduli of elasticity, but only on the ratio of moduli of elasticity. However, dependence on other parameters is more difficult to predict from the equations. We therefore performed a parametric study of how the opening distance responds to these input parameters (Table 1). Parameters were set at reference values and varied one by one. The reference values for the stem dimensions were close to the values measured experimentally (Table 2). The reference value for the ratio of moduli of elasticity was consistent with data in the literature (Réquilé et al. 2018). The reference cutting distance was zero, i.e., a symmetric cut. The reference for the maturation strain of phloem was arbitrarily set at $-1 \%$.

The response of the opening distance to input parameters is shown in Fig. 3. The response of the opening distance to the stem size (tissue proportions kept constant) is negative (Fig. 3A). This means that there is a size effect in the problem: all other parameters being constant, a bigger stem will have a lower opening distance. The opening distance directly depends on the size of the stem, not just on its dimension ratios. A similar size effect has been demonstrated in wood (Alméras and Fournier 2009; Alméras et al. 2018).

The response to the relative radius of the cambium (and therefore to the thickness of the phloem ring) is non-linear (Fig. 3B). It shows a maximum close to the experimentally observed value. The opening distance tends to zero in the two limit cases (values of 0.6 and 1.0) corresponding respectively to negligible xylem thickness and negligible phloem thickness. The response to the pith relative radius (for a given relative radius of phloem) is negative, meaning that the opening distance is larger if there is more xylem (Fig. 3C). The limit case for a value of 0.9 corresponds to the case in which the xylem
Table 2. Flax stem parameters from cross section analysis and calculated values of phloem maturation strain.

\begin{tabular}{ll}
\hline Parameter & Value \\
\hline Opening distance $(a ; \mathrm{mm})$ & $8.53 \pm 5.19$ \\
Stem radius $\left(R_{\text {stem }} ; \mathrm{mm}\right)$ & $0.93 \pm 0.18$ \\
Cambium radius $\left(R_{\text {cambium }} ; \mathrm{mm}\right)$ & $0.80 \pm 0.17$ \\
Pith radius $\left(R_{\text {pith }} ; \mathrm{mm}\right)$ & $0.53 \pm 0.16$ \\
Cambium relative radius $\left(R_{\text {cambium }}: R_{\text {stem }}\right)$ & $0.87 \pm 0.05$ \\
Pith relative radius $\left(R_{\text {pith }}: R_{\text {stem }}\right)$ & $0.57 \pm 0.07$ \\
Phloem maturation strain $\left(\alpha_{\text {phl }}^{\text {matur }} ; \%\right)$ & $-1.51 \pm 0.53$ \\
\hline
\end{tabular}

Note: Values are the mean values \pm SD; $n=14$.

thickness is negligible. In this case, the opening distance tends to zero.

The response to the ratio of moduli (Fig. 3D) is nonlinear and shows a maximum near 0.5. Near the reference value of 0.2 , the slope is quite strong, meaning that the result will be sensitive to the value set for this ratio. The opening distance tends to zero near a modulus ratio of zero, i.e., if xylem is not rigid. Taken together, the responses of the opening distance to the dimension ratios and modulus ratio show that the segment only opens if both tissues contribute to stem stiffness: if one tissue has negligible thickness or stiffness, no opening occurs.

The response to the cutting distance is shown in Fig. 3E. The opening distances of each side are shown along with the total opening distance. The opening distance of the small side is always larger than that of the big side. This difference between the opening distances of the two sides increases with the cutting distance. The total opening distance behaves grossly like the small side. It is maximum when the cut is made in the middle of the xylem. In this case, the opening distance is approximately 3 times that of the symmetric cut.

\section{Experimental validation of the method}

Figure 4A shows the typical appearance of a split flax stem segment. The opening of the segment is obvious and qualitatively demonstrates that some tension is induced in flax phloem during maturation. Indeed, the parametric study demonstrated that, for given tissue dimensions and modulus of elasticity, the opening distance is proportional to the maturation strain of phloem, so that no opening would occur if the maturation strain was zero.

Figure 4B shows an example of an asymmetric cut performed on a flax stem segment. It can be seen that the smaller split part has more curvature than the bigger part, and that the total opening distance is much larger than the opening distance obtained with a symmetric cut. These observations are in accordance with predictions made from the parametric study (Fig. 3E), and tend to validate the model.

The parametric study revealed that the opening distance strongly depends on stem dimension (Fig. 3A). Variations in the opening distance obtained experimentally are shown in Fig. 5A as a function of stem radius. An 
Fig. 3. Results of the parametric study. Response of opening distance to variations in (A) stem radius; (B) cambium relative radius, defining the proportion of phloem in the stem; $(C)$ pith relative radius, defining the proportion of xylem in the stem; (D) ratio of moduli of elasticity; (E) relative cutting distance (distance of the cutting line from the center of the stem divided by stem radius) in the case of an asymmetric cut. [Colour online.]
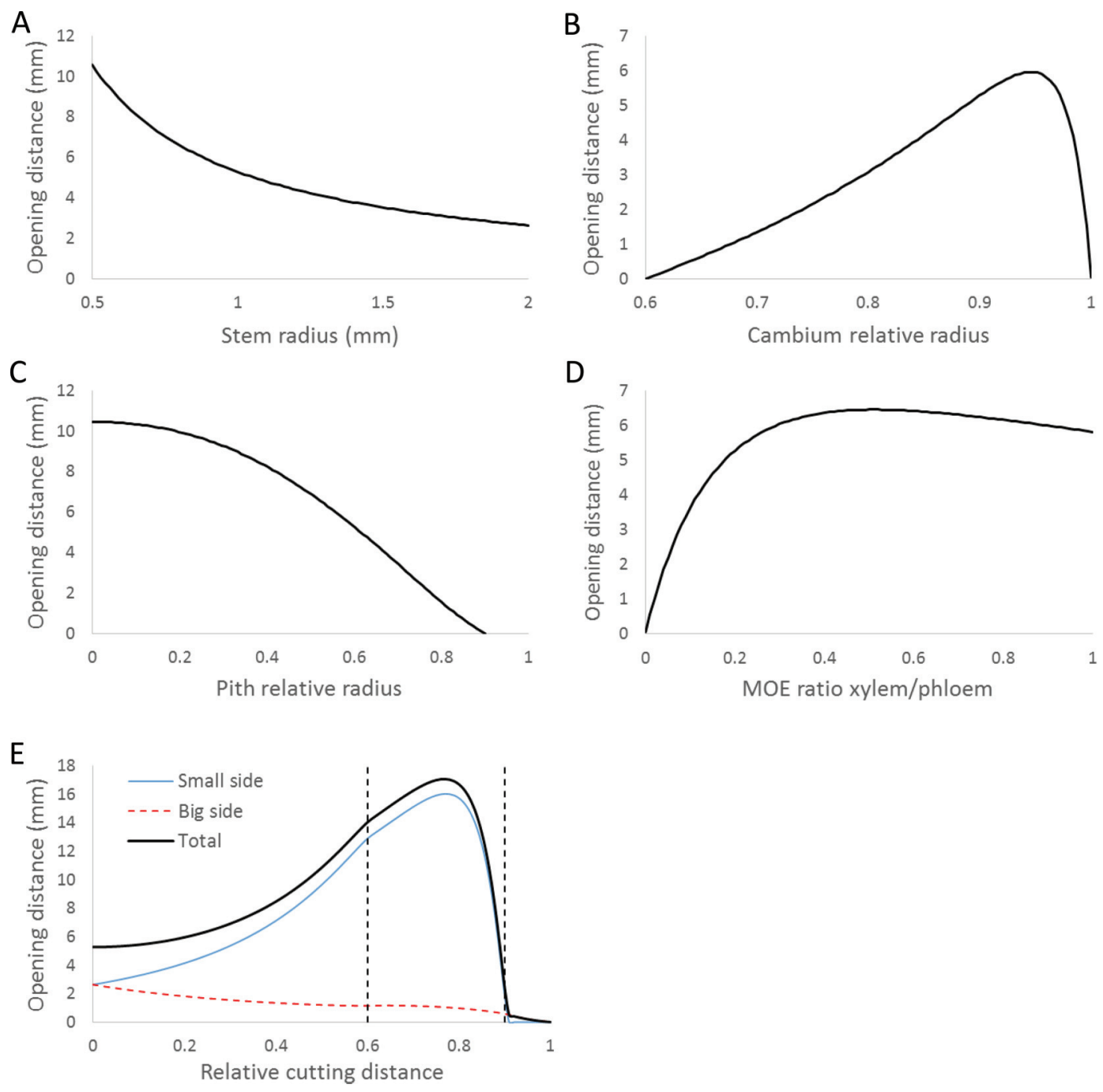

Fig. 4. Observed opening of a flax stem segment after symmetric splitting (A) and asymmetric splitting (B). [Colour online.]

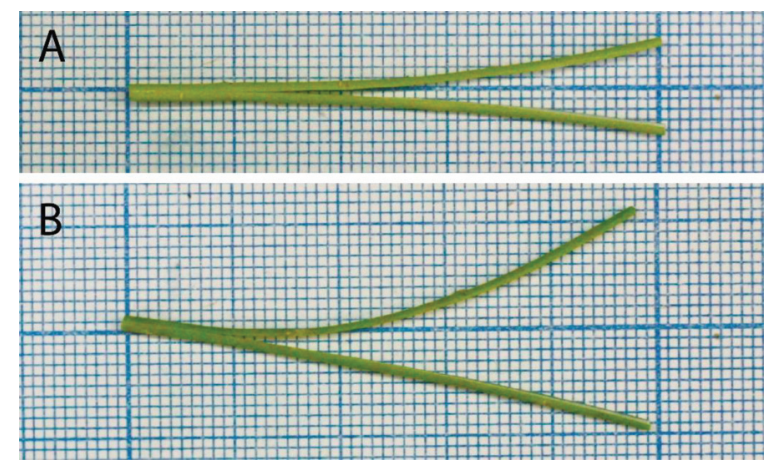

inverse relationship is obtained, very much like the predicted trend.

This clearly shows that it is not advisable to use the raw opening distance as a proxy for maturation strain. If

the opening distance had been used as a proxy for maturation strain, here we would conclude that it correlates with stem radius, whereas the correlation we observed is simply due to a "size effect": for a given maturation strain, the opening distance is smaller if the stem radius is larger. To account for this effect, it is necessary to carry out the calculations described in the present article, and to estimate the maturation strain rather than directly analyze the opening distance. Maturation strain is not subject to a size effect, so the maturation strain of stems of different sizes can be compared directly. Actually, once the maturation strain is computed, one can see that it does not correlate with stem size (Fig. 5B).

According to the parametric study (Figs. 3B and 3C) the proportion of xylem and phloem may have a strong influence on opening distance, and hence, on calculated strain. Our experimental data indeed show substantial variations in the stem, cambium, and pith radii among 
Fig. 5. (A) Opening distance of split flax stems at yellow ripeness stage as a function of stem radius. (B) Calculated maturation strain values as a function of the stem radii.
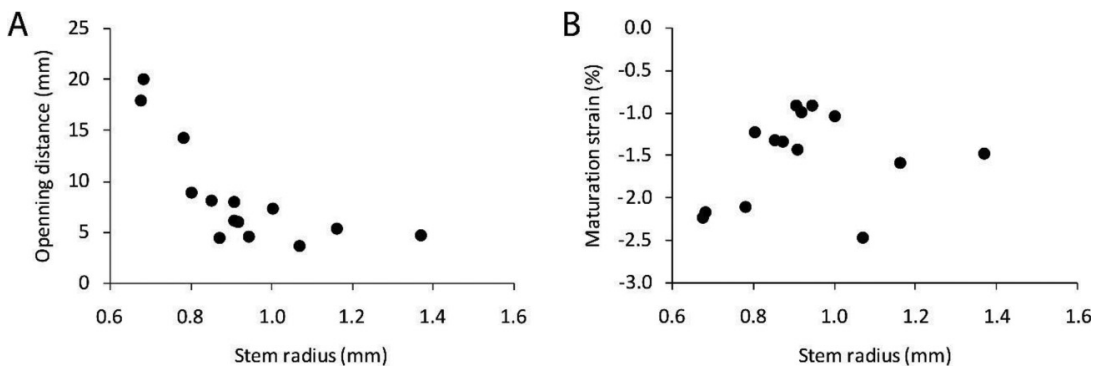

plants (Table 2). However, the ratios between these values demonstrate much less variability, indicating that the proportions of the tissue remain relatively constant in different plants at the same stage of development. This probably means that the difference in maturation strain values are not directly determined by the proportion of tissue.

\section{Discussion}

\section{Model limitations and possible error sources}

The splitting experiment demonstrates that flax phloem is under tension, and that this tension is enough to bend a flax stem. This bending can be observed experimentally because the distribution of tissues, and therefore of stresses, are neither uniform nor axially symmetric within a half section. Our inverse calculation enables the calculation of the relevant parameter causing this bending, i.e., the maturation strain of phloem. The estimated maturation strain of flax phloem ranges between $-0.9 \%$ and $-2.5 \%$, with a mean value of $-1.5 \%$. This maturation strain occurs inside the living plant during the maturation of phloem. As phloem distribution has axial symmetry within the living stem, maturation results in an axial contraction rather than in bending. This contraction is the part of phloem maturation strain that is expressed in vivo. Our calculation (numerical application of eq. 5 and eq. 6) shows that approximately two thirds of the maturation strain is expressed in vivo. This implies that only one third is still present as residual strain in the mature stem. Therefore, a hypothetical direct measurement of residual strains on the phloem part of the stem would largely underestimate the native value of the maturation strain. Our inverse method makes it possible to retrieve the initial value of the maturation strain, by taking advantage of the compressive stress appearing in xylem in response to the in vivo axial contraction of the stem.

However, this method relies on the measurement of input parameters (such as the dimensions and properties of the tissues) and the applicability of the hypotheses underlying the calculation. The parametric study provides information on the sensitivity of the results to input parameters. The non-dimensional sensitivity of each parameter was computed as the ratio of the relative variations in the output (opening distance) to that of the

input parameter. As the estimated maturation strain linearly depends on the opening distance, these figures also apply to the estimation of maturation strain.

The non-dimensional sensitivity to the stem radius is 1.0 , meaning the $1 \%$ error on the radius reflects a $1 \%$ error on estimated maturation strain. The non-dimensional sensitivity to the relative dimensions of the tissue is $\mathbf{2 . 0}$ for the pith relative radius and 3.8 for the cambium relative radius. The sensitivities are higher than 1 , showing that experimental error is amplified by the dependence on these parameters. However, the stem dimensions can be measured with good accuracy so that uncertainty on these parameters is probably the largest source of uncertainty in this experiment.

The distance of the cutting line from the center of the section should be controlled and set homogeneously along the cut segment. Both the parametric study (Fig. 3E) and the experimental results (Fig. 4) show that the opening distance can be strongly affected by asymmetrical cutting. However, for a symmetric cut, the sensitivity is zero (i.e., the response is flat, see Fig. 3E). This means that a small error in the cutting distance has almost no effect on the results. This low sensitivity is rather robust: for example, if the error on the distance is $10 \%$ of the radius, then the relative error on the estimated maturation strain is only $3 \%$.

We used literature data for the ratio of moduli of elasticity of the tissues, and the parametric study (Fig. 3D) showed that the response is sensitive to this parameter. This parameter was set at 0.2 (i.e., phloem was assumed to be five times stiffer than xylem) and its nondimensional sensitivity is 0.4 . This means that, if the real value of this parameter was 0.25 , then the estimated value of maturation strain would be reduced by $10 \%$ of its value. This would change the estimates slightly, but not the order of magnitude.

Another possible source of error is the applicability of hypotheses underlying the model. For example, we assumed that the section is sufficiently described by three layers (pith, xylem and phloem). The presence of other tissues such as cortex and epidermis was neglected. Pith stiffness was also neglected. These hypotheses seem reasonable for the flax variety we studied, but should be reconsidered if a different material is studied. We also 
made simplifying assumptions regarding the maturation of the tissues, namely that the xylem was fully mature during phloem maturation, and that any stress resulting from xylem maturation could be neglected. These simplifying assumptions are a possible source of error. The real kinetics of tissue maturation very probably results in stress gradients in both xylem and phloem, which were neglected here although they could contribute to the bending of the half-segments. Finally, our mechanical formulation is based on beam theory and focuses on longitudinal stress, whereas other components of stress (radial, tangential, and shear stresses) are non-zero, although they should be small compared with longitudinal stress.

\section{Tensile maturation strain in flax phloem}

There are striking similarities in the structure and chemical composition between G-fibers in flax phloem and in angiosperm tension wood (Gorshkova et al. 2012, 2015; Mellerowicz and Gorshkova 2012). The estimates of maturation strain for angiosperm tension wood vary depending on the measurement method. Using traditional stress-release methods, it typically ranges between $-0.2 \%$ and $-0.3 \%$ (e.g., Clair et al. 2006b), i.e., several times less than what we obtained for flax. More recently, an inverse method, analogous to the one developed here for flax, enabled estimation of the maturation strain of tension wood inside young stems subjected to a strong gravitropic stimulus (tilted and staked) and therefore developed severe tension wood. Maturation strain of tension wood measured with this method ranged between $-0.1 \%$ and $-0.7 \%$ for poplar stems and between $-0.3 \%$ and $-1.3 \%$ for a diversity of tropical angiosperm species (Alméras et al. 2018). The mean maturation strain we obtained for flax $(-1.5 \%)$ is slightly higher than the highest value observed in angiosperm tension wood. Given the abovementioned considerations about possible experimental and model errors, this difference may not be significant. This tends to confirm that the mechanisms creating maturation strain could be the same for flax phloem G-layers and for tension wood G-layers.

Variations in maturation strain between plants had no direct link either with stem size or with the proportion of tissue (Fig. 5B; Table 2), meaning another parameter (or parameters) determine the magnitude of maturation strain. One of these parameters may be the surface area of the G-layers, which are considered as the primary source of maturation strain (Gorshkova et al. 2018). Their surface area is not the same as that of phloem and may not even be proportional to it in different plants. Further investigations involving precise measurements of G-layer area at different developmental stages are necessary. The experimental strategy and theoretical model for evaluation of maturation strain are now available for flax and other plants with analogous anatomy.

\section{Funding information}

This work was partially supported by the Russian Science Foundation (project number 18-14-00168, data processing). Plant material growing and collecting, experiments on longitudinal splitting, and microscopy were performed at financial support from the government assignment for FRC Kazan Scientific Center of RAS.

\section{References}

Abasolo, W.P., Yoshida, M., Yamamoto, H., and Okuyama, T. 2009. Stress generation in aerial roots of Ficus elastica (Moraceae). IAWA J. 30(2): 216-224. doi:10.1163/2294193290000216.

Ahmed, S., and Ulven, C.A. 2018. Dynamic in-situ observation on the failure mechanism of flax fiber through scanning electron microscopy. Fibers, 6(1): 17. doi:10.3390/fib6010017.

Alméras, T., and Fournier, M. 2009. Biomechanical design and long-term stability of trees: morphological and wood traits involved in the balance between weight increase and the gravitropic reaction. J. Theor. Biol. 256: 370-381. doi:10.1016/ j.jtbi.2008.10.011. PMID:19013473.

Alméras, T., Derycke, M., Jaouen, G., Beauchêne, J., and Fournier, M. 2009. Functional diversity in gravitropic reaction among tropical seedlings in relation to ecological and developmental traits. J. Exp. Bot. 60(15): 4397-4410. doi:10. 1093/jxb/erp276. PMID:19759096.

Alméras, T., Ghislain, B., Clair, B., Secerovic, A., Pilate, G., and Fournier, M. 2018. Quantifying the motor power of trees. Trees, 32: 689-702. doi:10.1007/s00468-018-1662-7.

Archer, R.R. 1986. Growth stresses and strains in trees. Springer, Berlin, Germany.

Arnould, O., Siniscalco, D., Bourmaud, A., Le Duigou, A., and Baley, C. 2017. Better insight into the nano-mechanical properties of flax fibre cell walls. Ind. Crops Prod. 97: 224-228. doi:10.1016/j.indcrop.2016.12.020.

Aslan, A., Chinga-Carrasco, G., Sørensen, B.F., and Madsen, B. 2011. Strength variability of single flax fibres. J. Mater. Sci. 46: 6344-6354. doi:10.1007/s10853-011-5581-x.

Baley, C., Goudenhooft, C., Gibaud, M., and Bourmaud, A. 2018. Flax stems: from a specific architecture to an instructive model for bioinspired composite structures. Bioinspir. Biomim. 13: 026007. doi:10.1088/1748-3190/aaa6b7. PMID: 29319533.

Bos, H.L., van Den Oever, M.J.A., and Peters, O.C.J.J. 2002. Tensile and compressive properties of flax fibres for natural fibre reinforced composites. J. Mater. Sci. 37(8): 1683-1692. doi:10. 1023/A:1014925621252.

Bourmaud, A., Beaugrand, J., Shah, D.U., Placet, V., and Baley, C. 2018. Towards the design of high-performance plant fibre composites. Prog. Mater. Sci. 97: 347-408. doi:10.1016/j. pmatsci.2018.05.005.

Clair, B., Alméras, T., Yamamoto, H., Okuyama, T., and Sugiyama, J. 2006a. Mechanical behavior of cellulose microfibrils in tension wood, in relation with maturation stress generation. Biophys. J. 91(3): 1128-1135. doi:10.1529/biophysj. 105.078485. PMID:16698777.

Clair, B., Ruelle, J., Beauchêne, J., Prévost, M.F., and Fournier-Djimbi, M. 2006b. Tension wood and opposite wood in 21 tropical rain forest species. 1. Occurrence and efficiency of the G-layer. IAWA J. 27: 329-338. doi:10.1515/HF.2003.028.

Clair, B., Alméras, T., Pilate, G., Jullien, D., Sugiyama, J., and Riekel, C. 2011. Maturation stress generation in poplar tension wood studied by synchrotron radiation microdiffraction. Plant Physiol. 155(1): 562-570. doi:10.1104/pp.110.167270. PMID:21068364.

Clair, B., Alteyrac, J., Gronvold, A., Espejo, J., Chanson, B., and 
Alméras, T. 2013. Patterns of longitudinal and tangential maturation stresses in Eucalyptus nitens plantation trees. Ann. For. Sci. 70: 801-811. doi:10.1007/s13595-013-0318-4.

Clair, B., Ghislain, B., Prunier, J., Lehnebach, R., Beauchêne, J., and Alméras, T. 2019. Mechanical contribution of secondary phloem to postural control in trees: the bark side of the force. New Phytol. 221(1): 209-217. doi:10.1111/nph.15375. PMID:30076782.

Dadswell, H.E., and Wardrop, A.B. 1955. The structure and properties of tension wood. Holzforschung, 9(4): 97-104. doi:10. 1515/hfsg.1955.9.4.97.

Esau, K. 1943. Vascular differentiation in the vegetative shoot of Linum. III. The origin of the bast fibers. Am. J. Bot. 30: 579586. doi:10.1002/j.1537-2197.1943.tb10302.x.

Fisher, J.B. 1982. A survey of buttresses and aerial roots of tropical trees for presence of reaction wood. Biotropica, 14(1): 56-61. doi:10.2307/2387760.

Fisher, J.B. 2008. Anatomy of axis contraction in seedlings from a fire prone habitat. Am. J. Bot. 95(11): 1337-1348. doi:10.3732/ ajb.0800083. PMID:21628143.

Gorshkova, T.A., Salnikov, V.V., Chemikosova, S.B., Ageeva, M.V., Pavlencheva, N.V., and van Dam, J.E.G. 2003. The snap point: a transient point in Linum usitatissimum bast fiber development. Ind. Crop Prod. 18(3): 213-221. doi:10.1016/ S0926-6690(03)00043-8.

Gorshkova, T., Brutch, N., Chabbert, B., Deyholos, M., Hayashi, T., Lev-Yadun, S., et al. 2012. Plant fiber formation: state of the art, recent and expected progress, and open questions. Crit. Rev. Plant Sci. 31: 201-228. doi:10.1080/07352689. 2011.616096.

Gorshkova, T., Mokshina, N., Chernova, T., Ibragimova, N., Salnikov, V., Mikshina, P., et al. 2015. Aspen tension wood fibers contain $\beta$-( $1 \rightarrow 4)$-galactans and acidic arabinogalactans retained by cellulose microfibrils in gelatinous walls. Plant Physiol. 169: 2048-2063. doi:10.1104/pp.15.00690. PMID: 26378099.

Gorshkova, T., Chernova, T., Mokshina, N., Ageeva, M., and Mikshina, P. 2018. Plant 'muscles': fibers with a tertiary cell wall. New Phytol. 218(1): 66-72. doi:10.1111/nph.14997. PMID: 29364532.

Goudenhooft, C., Bourmaud, A., and Baley, C. 2017. Varietal selection of flax over time: Evolution of plant architecture related to influence on the mechanical properties of fibers. Ind. Crops Prod. 97: 56-64. doi:10.1016/j.indcrop.2016.11.062.

Goudenhooft, C., Siniscalco, D., Arnould, O., Bourmaud, A., Sire, O., Gorshkova, T., and Baley, C. 2018. Investigation of the mechanical properties of flax cell walls during plant development: The relation between performance and cell wall structure. Fibers, 6: 6. doi:10.3390/fib6010006.

Goudenhooft, C., Alméras, T., Bourmaud, A., and Baley, C. 2019. The remarkable slenderness of flax plant and pertinent factors affecting its mechanical stability. Biosyst. Eng. 178: 1-8. doi:10.1016/j.biosystemseng.2018.10.015.

Jullien, D., and Gril, J. 2008. Growth strain assessment at the periphery of small-diameter trees using the two-grooves method: influence of operating parameters estimated by numerical simulations. Wood Sci. Technol. 42: 551-565. doi:10. 1007/s00226-008-0202-9.

Mellerowicz, E.J., and Gorshkova, T.A. 2012. Tensional stress generation in gelatinous fibres: a review and possible mechanism based on cell-wall structure and composition. J. Exp. Bot. 63: 551-565. doi:10.1093/jxb/err339. PMID:22090441.

Réquilé, S., Goudenhooft, C., Bourmaud, A., Le Duigou, A., and
Baley, C. 2018. Exploring the link between flexural behaviour of hemp and flax stems and fibre stiffness. Ind. Crops Prod. 113: 179-186. doi:10.1016/j.indcrop.2018.01.035.

Schneider, C.A., Rasband, W.S., and Eliceiri, K.W. 2012. NIH Image to ImageJ: 25 years of image analysis. Nat. Methods, 9: 671-675. doi:10.1038/nmeth.2089. PMID:22930834.

Schreiber, N., Gierlinger, N., Pütz, N., Fratzl, P., Neinhuis, C., and Burgert, I. 2010. G-fibres in storage roots of Trifolium pratense (Fabaceae): tensile stress generators for contraction. Plant J. 61: 854-861. doi:10.1111/j.1365-313X.2009.04115.x. PMID:20030750.

Tanguy, M., Bourmaud, A., and Baley, C. 2016. Plant cell walls to reinforce composite materials: Relationship between nanoindentation and tensile modulus. Mater. Lett. 167: 161-164. doi:10.1016/j.matlet.2015.12.167.

Yoshida, M., and Okuyama, T. 2002. Techniques for measuring growth stress on the xylem surface using strain and dial gauges. Holzforschung, 56: 461-467. doi:10.1515/HF.2002.071.

\section{Appendix A}

Step by step demonstration of equations From eq. 3 to eq. 4 :

$$
\begin{aligned}
& \iint_{\text {xylem }+ \text { phloem }} \sigma^{\text {in vivo }} d A=0 \\
& \Rightarrow \iint_{\text {xylem }} \sigma_{\text {xyl }}^{\text {in vivo }} d A+\iint_{\text {phloem }} \sigma_{\text {phl }}^{\text {in vivo }} d A=0
\end{aligned}
$$

Injecting constitutive eqs. $2 a$ and $2 b$ and recalling that the moduli of elasticity and maturation stress are uniform within tissues, we have:

$$
\begin{aligned}
& E_{\text {xyl }} \varepsilon_{\text {stem }}^{\text {in vivo }} \iint_{\text {xylem }} d A+E_{\text {phl }} \varepsilon_{\text {stem }}^{\text {in vivo }} \iint_{\text {phloem }} d A \\
& -E_{\mathrm{phl}} \alpha_{\mathrm{phl}}^{\text {matur }} \iint_{\text {phloem }} d A=0 \\
& \Rightarrow E_{\mathrm{xyl}} \varepsilon_{\mathrm{stem}}^{\text {in vivo }} A_{\mathrm{xyl}}+E_{\mathrm{phl}} \varepsilon_{\mathrm{stem}}^{\text {in vivo }} A_{\mathrm{phl}}=E_{\mathrm{phl}} \alpha_{\mathrm{phl}}^{\text {matur }} A_{\mathrm{phl}}
\end{aligned}
$$

Solving for $\varepsilon_{\text {stem }}^{\text {in vivo }}$, we obtain:

(4)

$$
\varepsilon_{\text {stem }}^{\text {in vivo }}=\alpha_{\mathrm{phl}}^{\text {matur }} E_{\mathrm{phl}} A_{\mathrm{phl}} /\left(E_{\mathrm{xyl}} A_{\mathrm{xyl}}+E_{\mathrm{phl}} A_{\mathrm{phl}}\right)
$$

From eq. 10 to eq. 11:

$$
\begin{aligned}
& \left\{\begin{array}{l}
\iint_{\text {half section }} \sigma^{\text {split }} d A=0 \\
\iint_{\text {half section }} x \sigma^{\text {split }} d A=0
\end{array}\right. \\
& \Rightarrow\left\{\begin{array}{c}
\iint_{\text {half xylem }} \sigma^{\text {split }} d A+\iint_{\text {half phloem }} \sigma^{\text {split }} d A=0 \\
\iint_{\text {half xylem }} x \sigma^{\text {split }} d A+\iint_{\text {half phloem }} x \sigma^{\text {split }} d A=0
\end{array}\right.
\end{aligned}
$$

Injecting eqs. $8 a$ and $8 b$ we obtain: 
Fig. A1. Moments of area for an asymmetric cut: (A) one circle, (B) two concentric circles of radii $R_{\text {in }}$ and $R_{\text {out }}$, and cut at a distance $d$ from the center, (C) five cases of asymmetric cut. [Colour online.]

A

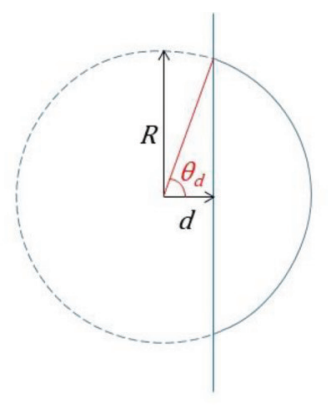

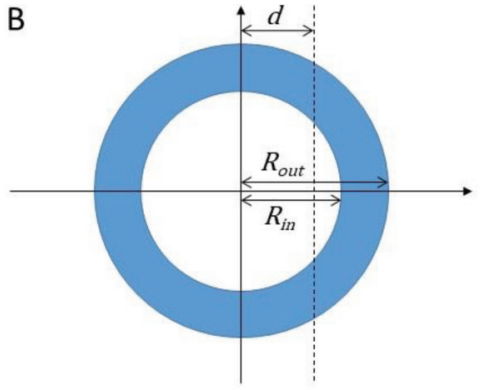

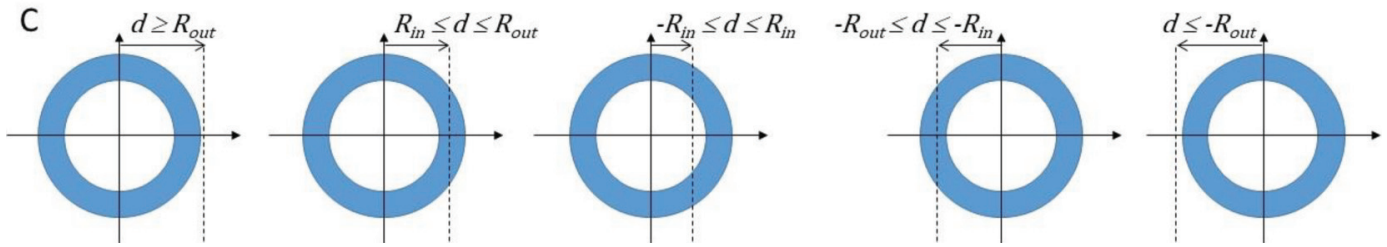

$$
\left\{\begin{array}{c}
\iint_{\text {half xylem }} E_{x y l} \varepsilon^{\text {split }}(x, y) d A+\iint_{\text {half phloem }} E_{\text {phl }} \varepsilon^{\text {split }}(x, y) d A+\iint_{\text {half xylem }} \sigma_{\text {xyl }}^{\text {in vivo }} d A+\iint_{\text {half phloem }} \sigma_{\text {phl }}^{\text {in vivo }} d A=0 \\
\iint_{\text {half xylem }} E_{\text {xyl }} \varepsilon^{\text {split }}(x, y) x d A+\iint_{\text {half phloem }} E_{\text {phl }} \varepsilon^{\text {split }}(x, y) x d A+\iint_{\text {half xylem }} \sigma_{\text {xyl }}^{\text {in vivo }} x d A+\iint_{\text {half phloem }} \sigma_{\text {phl }}^{\text {in vivo } x d A=0}
\end{array}\right.
$$

Injecting eq. 9, we obtain:

$$
\begin{aligned}
& \left\{E_{\text {xyl }} \iint_{\text {half xylem }}\left(\varepsilon_{\text {pith }}^{\text {split }}-x C\right) d A+E_{\text {phl }} \iint_{\text {half phloem }}\left(\varepsilon_{\text {pith }}^{\text {split }}-x C\right) d A+\sigma_{\text {xyl }}^{\text {in vivo }} \iint_{\text {half xylem }} d A+\sigma_{\text {phl }}^{\text {in vivo }} \iint_{\text {half phloem }} d A=0\right. \\
& \left\{E_{\text {xyl }} \iint_{\text {half xylem }}\left(\varepsilon_{\text {pith }}^{\text {split }}-x C\right) x d A+E_{\text {phl }} \iint_{\text {half phloem }}\left(\varepsilon_{\text {pith }}^{\text {split }}-x C\right) x d A+\sigma_{\text {xyl }}^{\text {in vivo }} \iint_{\text {half xylem }} x d A+\sigma_{\text {phl }}^{\text {in vivo }} \iint_{\text {half phloem }} x d A=0\right.
\end{aligned}
$$

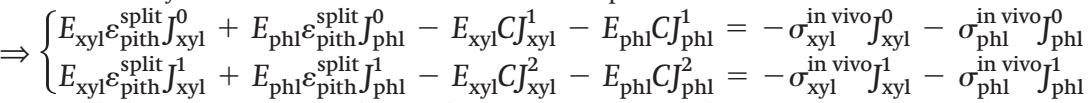

$$
\begin{aligned}
& \Rightarrow\left\{\varepsilon_{\text {pith }}^{\text {split }}\left(E_{\mathrm{xyl}} J_{\mathrm{xyl}}^{0}+E_{\mathrm{phl}} J_{\mathrm{phl}}^{0}\right)+C\left(-E_{\mathrm{xyl}} J_{\mathrm{xyl}}^{1}-E_{\mathrm{phl}} J_{\mathrm{phl}}^{1}\right)=-\sigma_{\mathrm{xyl}}^{\text {in vivo }} J_{\mathrm{xyl}}^{0}-\sigma_{\text {phl }}^{\text {in vivo }} J_{\mathrm{phl}}^{0}\right.
\end{aligned}
$$

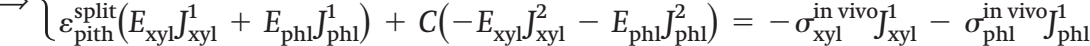

$$
\begin{aligned}
& \Rightarrow\left(\begin{array}{cc}
E_{\mathrm{xyl}} J_{\mathrm{xyl}}^{0}+E_{\mathrm{phl}} J_{\mathrm{phl}}^{0} & -E_{\mathrm{xyl}} J_{\mathrm{xyl}}^{1}-E_{\mathrm{phl}} J_{\mathrm{phl}}^{1} \\
-E_{\mathrm{xyl}} J_{\mathrm{xyl}}^{1}-E_{\mathrm{phl}} J_{\mathrm{phl}}^{1} & E_{\mathrm{xyl}} J_{\mathrm{xyl}}^{2}+E_{\mathrm{phl}} J_{\mathrm{phl}}^{2}
\end{array}\right)\left(\begin{array}{c}
\varepsilon_{\mathrm{pith}}^{\mathrm{split}} \\
C
\end{array}\right)=-\sigma_{\mathrm{xyl}}^{\mathrm{in} \mathrm{vivo}}\left(\begin{array}{c}
J_{\mathrm{xyl}}^{0} \\
-J_{\mathrm{xyl}}^{1}
\end{array}\right)-\sigma_{\mathrm{phl}}^{\mathrm{in} \mathrm{vivo}}\left(\begin{array}{c}
J_{\mathrm{phl}}^{0} \\
-J_{\mathrm{phl}}^{1}
\end{array}\right)
\end{aligned}
$$

\section{Moments of area of the tissues for cylindrical geometry}

Let us consider a circle of radius $R$ cut at a distance $d$ from its center $(-R<d<R)$ (Fig. A1A). The moments of area of the right part of the cut circle (relative to the line passing through the center of the circle) are given below:

$$
\begin{aligned}
& J_{*}^{0}(R, d)=R^{2}\left[\theta_{d}-\sin \left(2 \theta_{d}\right) / 2\right] \\
& J_{*}^{1}(R, d)=\frac{2}{3} R^{3} \sin ^{3}\left(\theta_{d}\right) \\
& J_{*}^{2}(R, d)=\frac{1}{4} R^{4}\left[\theta_{d}-\sin \left(4 \theta_{d}\right) / 4\right]
\end{aligned}
$$

with: $\theta_{d}=\operatorname{acos}(d / R)$.

Each tissue (xylem and phloem) is defined by its boundary circles (Fig. A1B). Let us consider a ring of tissue defined by $R_{\text {in }}$ and $R_{\text {out }}$. The moment of area of its cut right part, $J_{\text {right }}^{n}\left(R_{\text {in }}, R_{\text {out }}, d\right)$, can be deduced from the superposition principle, after considering the following cases (Fig. A1C):

$$
\begin{array}{ll}
\text { If } d \geq R_{\text {out }}: & J_{\text {right }}^{n}=0 \\
\text { If } R_{\text {in }} \leq d \leq R_{\text {out }}: & J_{\text {right }}^{n}=J_{*}^{n}\left(R_{\text {out }}, d\right) \\
\text { If }-R_{\text {in }} \leq d \leq R_{\text {in }}: & J_{\text {right }}^{n}=J_{*}^{n}\left(R_{\text {out }}, d\right)-J_{*}^{n}\left(R_{\text {in }}, d\right) \\
\text { If }-R_{\text {out }} \leq d \leq-R_{\text {in }}: & J_{\text {right }}^{n}=J_{*}^{n}\left(R_{\text {out }}, d\right)-J_{*}^{n}\left(R_{\text {in }},-R_{\text {in }}\right) \\
\text { If } d \leq-R_{\text {out }}: & J_{\text {right }}^{n}=J_{*}^{n}\left(R_{\text {out }},-R_{\text {out }}\right)-J_{*}^{n}\left(R_{\text {in }},-R_{\text {in }}\right)
\end{array}
$$

The moments of area of the left part can be deduced by symmetry:

$$
\begin{aligned}
& J_{\text {left }}^{0}\left(R_{\text {in }}, R_{\text {out }}, d\right)=J_{\text {right }}^{0}\left(R_{\text {in }}, R_{\text {out }},-d\right) \\
& J_{\text {left }}^{1}\left(R_{\text {in }}, R_{\text {out }}, d\right)=-J_{\text {right }}^{1}\left(R_{\text {in }}, R_{\text {out }},-d\right) \\
& J_{\text {left }}^{2}\left(R_{\text {in }}, R_{\text {out }}, d\right)=J_{\text {right }}^{2}\left(R_{\text {in }}, R_{\text {out }},-d\right)
\end{aligned}
$$

